\title{
An empirical test of Mowrer's theory of imitation
}

\author{
RICHARD A. DUBANOSKI* \\ University of Hawaii, Honolulu, Hawaii 96822
}

It would be predicted from Mowrer's theory of imitation that children who receive candy while watching a model make specific responses would match those specific responses more frequently than would children who did not receive candy. The results of this experiment offered no support for this hypothesis. Mere frequent exposure to the specific responses facilitated the occurrence of imitation.

Mowrer (1950, 1960) posited a secondary reinforcement theory of imitative learning. As a consequence of associating positive rewards with certain responses, these responses acquire secondary reinforcing properties. Thus, when an individual subsequently performs similar responses (i.e., imitates), he will receive immediate reinforcement due to secondary reinforcing properties of those responses. The occurrence of imitative responding, therefore, should be facilitated by associating responses with positive rewards.

The development of Mowrer's theory was related to training a mynah bird to talk (Mowrer, 1950). In this case, the model repeated certain words while the bird was being fed. It appeared that this procedure was effective in producing imitative behavior in the bird. But Mowrer (1950, p. 690) was aware that he had "done nothing that might be called an experiment."

Certain research offers no support for Mowrer's theory. For example, Mowrer reported a study by Zimmerman (1958) in which dogs could not be trained to make imitative behaviors, using a procedure similar to that used with the mynah bird. In a study by Foss (1964), mynah birds were reinforced when one tone was played and not reinforced when another tone was played. The birds imitated both the reinforced and the nonreinforced tones equally well; thus, the association between primary reinforcement and the responses to be imitated did not facilitate the occurrence of imitative responses. Unfortunately, Foss confounded reinforcement with the time of response presentation, i.e., the bird always heard the tone associated with reinforcement at midday and the tone associated with no reinforcement at dusk. Thus, the effect of the

*This research was supported, in part, by a Biomedical Support grant from Office Research Adminsitration, University of Hawaii. reinforced tones may have generalized to the nonreinforced tones.

The present study was an empirical test of Mowrer's secondary reinforcement theory of imitation using young children. Ss were either given candy in the presence of modeled responses or given nothing in the presence of these responses. According to Mowrer's theory, the reinforced group should imitate the modeled responses more than the nonreinforced group.

\section{METHOD}

A total of 64 children from Grades 1 and 2 served as Ss; half were males and half were females. The Ss were assigned randomly to one of four experimental conditions, with the one restriction that there be an equal number of boys and girls in each condition.

The apparatus consisted of a $33 \times 35 \mathrm{~cm}$ panel containing two manipulanda: a button that could be pushed in and a lever that could be pulled down. For one-half of the Ss in each condition, the button was located on the left side of the panel and the lever on the right side. For the other half, the button was on the right side and the lever on the left side. Each manipulanda could activate a candy dispenser that would deliver a candy to a tray located at the bottom of the panel. Responses to each manipulanda were recorded on an automatic counter. The panel also contained a small light and buzzer that signaled the beginning of each trial.

Each $S$ in the model-reinforcement condition ( $M-R$ condition) was seated in front of the panel and told that every time the light and buzzer went on, the $\mathrm{E}$ would play with either the lever or the button. The E demonstrated two responses to each manipulanda. The Ss were also told that sometimes when $E$ played a candy would come out of the tray and they could eat it. Then, for one-half of the Ss, the E pulled the lever 16 times, and, for the other half of the Ss, the E pushed the button 16 times. After each response, the $S$ received a candy.

In the model-no reinforcement condition (M-NR condition), the Ss followed a procedure similar to that of the M-R condition, except that there were no instructions on the delivery of candy and the Ss did not receive any candy following the E's responses. In this condition, therefore, the Ss watched the $E$ either push the button 16 times or pull the lever 16 times. The model-control condition (M-C condition) consisted of Ss observing the $E$ manipulate both the lever and the button 8 times with no candy delivered to the Ss. In the no model condition (NM condition), the Ss watched the $E$ play a game in which he placed 16 blocks on a same number of dowels.

Following one of these demonstrations by the $E$, each $S$ was told that he could now play the panel game. The $S s$ in the M-R condition were first told that the $E$ was going to close the candy tray and lock it so it could not be opened. All the Ss were told that every time the light and buzzer came on they were to play with either the button or the lever. For the Ss in the NM condition, the $E$ demonstrated how the lever and button could be manipulated; in the other conditions, the $\mathbf{E}$ just pointed to the manipulanda. The $E$ left the experimental room and the $\mathrm{Ss}$ were given 30 trials on the task.

The number of critical responses was recorded during the 30 trials. A critical response in the M-R and M-NR conditions was a response demonstrated by the $S$ that matched the response performed by the $\mathrm{E}$. For one-half of the Ss in the M-C and NM conditions, the lever response was designated as the critical response, and, for the other half of the Ss in these conditions, the button response was the critical response.

After the Ss performed the task, they were asked some questions. All the Ss were asked how the game could be played each time the light and buzzer went on. Every S demonstrated that he or she knew how the game was played, i.e., push the button or pull the lever. The $S s$ in the $M-R$ condition were also asked whether they received candy after the E played with the lever or the button. Each $S$ correctly identified which manipulandum was associated with the candy.

\section{RESULTS}

The means and standard deviations for the frequency of critical responses for all conditions are presented in Table 1. It is evident that the amount of critical responses in the $M-R$ and $M-N R$ conditions were quite similar and greater than in the M-C and NM conditions. The analysis of variance revealed that only the main effect of experimental condition was significant $(F=5.30, \mathrm{df}=3 / 56$, 
Table 1

Means and Standard Deviations for Fre quency of Critical Responses

\begin{tabular}{llll}
\hline $\begin{array}{c}\text { Condi- } \\
\text { tion }\end{array}$ & N & Mean & SD \\
\hline M-R & 16 & 19.52 & 5.83 \\
M-NR & 16 & 19.19 & 6.16 \\
M-C & 16 & 14.44 & 1.19 \\
NM & 16 & 15.31 & 1.04 \\
\hline
\end{tabular}

p $<.005)$. Follow-up analyses (Fisher's least significant difference procedure) revealed that there were significant differences $(p<.05)$ between the $M-R$ condition and either the M-C or NM condition. The M-NR condition was also significantly different from either the M-C or NM condition. There was no significant difference between the M-R and M-NR conditions. No other effects (Sex or Experimental Condition by Sex interaction) or comparisons were statistically significant.

\section{DISCUSSION}

Since there was no significant difference between the $M-R$ and the M-NR conditions, this study offered no support for Mowrer's secondary reinforcement theory of imitation. Associating rewarding stimuli (i.e., candy) with a certain response did not facilitate the occurrence of the imitation. The results of this study corroborate those of previous studies, which have used animals as Ss (Foss, 1964; Zimmerman, 1958).

There are four possible explanations to account for the lack of the effect. (1) Candy was an ineffective stimulus for children of this age. A pilot study with children of the same age, however, demonstrated that candy facilitated discrimination learning (i.e., served as a reinforcer). Candy, therefore, should have served as an effective rewarding stimulus to associate with the responses to be imitated. (2) The number of pairings (16) between the candy and the responses was not sufficient to produce the effect. A few Ss were used in a follow-up study in which there were either 48 pairings between the candy and the responses or 48 trials with no pairing. No differences were found between these two groups; thus, the number of pairings (at least up to 48) did not seem to account for the lack of effect. (3) The model himself might have been rewarding. The association between the model and the responses was enough to produce secondary reinforcing properties in the responses. Although this is passible, the model was told to interact minimally with the Ss throughout the experiment. (4) The reinforcement in the $M-R$ condition may have been masked by a prior history of reinforcement for imitation. It is most likely that during socialization all the Ss were trained to imitate; therefore, the reinforcement delivered during the experiment did not make a sufficient addition.

The greater frequency of critical responses in the M-NR condition than in either the $\mathrm{M}-\mathrm{C}$ or the $\mathrm{NM}$ condition indicates that just observing a model performing these responses frequently facilitates the occurrence of imitative responding. Several studies, in fact, have shown that mere observation of modeled responses facilitates imitation (e.g., Dubanoski \& Parton, 1971). Again, this effect may occur because the Ss used in this study have had a history of being reinforced for imitation. Thus, in the experimental setting observation of the responses would be enough to produce imitation.

Although frequent observation of the modeled responses facilitated the occurrence of critical responses, the Ss in the $M-R$ and the $M-N R$ conditions performed many noncritical responses. This might be due to satiation of producing critical responses and the novelty of producing noncritical responses. When the 30 test trials were divided into three trial blocks of 10 trials each, there was a relatively large number of critical responses in Trial Block 1 (a mean of 7.0 out of 10), a low number in Trial Block 2 (5.9), and an intermediate number in Trial Block 3 (6.5) for the $S s$ in the $M-R$ and M-NR conditions. The drop from Trial Block 1 to Trial Block 2 lends some support to the possibility that $S$ s may have become satiated in performing critical responses after an initial period of responding. Also, because the $\mathrm{Ss}$ did not frequently perform the noncritical responses at the beginning, the novelty of performing these responses may also account for some of the noncritical responding. The responding for $\mathrm{M}-\mathrm{C}$ and NM conditions showed a fairly consistent pattern across trial blocks, and the average number of critical responses for the two conditions was 4.8, 5.0, and 5.2 for Trial Hlocks 1, 2, and 3 , respectively.

\section{REFERENCES}

DUBANOSKT, $R$ A \& PARTON D A. Effect of the presence of a buman model on imitative behavior in children. Developmental Psychology, 1971, 4, 463-468.

Foss, B. M. Mimiery in mynahs (Graculas religiosa): A test of Mowrer's theory. British Journal of Psychology, 1964, 55, 85-88.

MOWRER, O. H. Learning theory and personality dynamics. New York: Ronald pressonality 1950.

MOWRER, O. H. Learning theory and the symbolic processes. New York: Wiley, 1960.

ZIMMERMAN, D. W. An unsuccessful attempt, based on the autism theory of language learning, to teach dogs to bark instrumentally. Unpublished manuscript, University of Illinois, 1958. Cited by 0 . H. Mowrer, Leaming theory and the symbolic processes. New York: Wiley, 1960. P. 78 . 